\title{
Particle optical backscattering along a chlorophyll gradient in the upper layer of the eastern South Pacific Ocean
}

\author{
Y. Huot ${ }^{1}$, A. Morel $^{1}$, M. S. Twardowski ${ }^{2}$, D. Stramski ${ }^{3}$, and R. A. Reynolds ${ }^{3}$ \\ ${ }^{1}$ CNRS, Laboratoire d'Océanographie de Villefranche, 06230 Villefranche-sur-mer, France; Université Pierre et Marie \\ Curie-Paris 6, Laboratoire d'Océanographie de Villefranche, 06230 Villefranche-sur-mer, France \\ ${ }^{2}$ Department of Research, WET Labs, Inc., 165 Dean Knauss Dr., Narragansett, RI 02882, USA \\ ${ }^{3}$ Marine Physical Laboratory, Scripps Institution of Oceanography, University of California at San Diego, La Jolla, CA \\ 92093-0238, USA
}

Received: 13 November 2007 - Published in Biogeosciences Discuss.: 3 December 2007

Revised: 12 March 2008 - Accepted: 13 March 2008 - Published: 7 April 2008

\begin{abstract}
The particulate scattering, $b_{p}$, and backscattering, $b_{b p}$, coefficients are determined by the concentration and physical properties of suspended particles in the ocean. They provide a simple description of the influence of these particles on the scattering of light within the water column. For the remote observation of ocean color, $b_{b p}$ along with the total absorption coefficient govern the amount and spectral qualities of light leaving the sea surface. However, for the construction and validation of ocean color models measurements of $b_{b p}$ are still lacking, especially at low chlorophyll $a$ concentrations ([Chl]). Here, we examine the relationships between spectral $b_{b p}$ and $b_{p}$ vs. [Chl] along an $8000 \mathrm{~km}$ transect crossing the Case 1 waters of the eastern South Pacific Gyre. In these waters, over the entire range of [Chl] encountered $\left(\sim 0.02-2 \mathrm{mg} \mathrm{m}^{-3}\right)$, both $b_{b p}$ and $b_{p}$ can be related to [Chl] by power functions (i.e. $b_{p}$ or $b_{b p}=\alpha[\mathrm{Chl}]^{\beta}$ ). Regression analyses are carried out to provide the parameters $\alpha$ and $\beta$ for several wavelengths throughout the visible for both $b_{b p}$ and $b_{p}$. When applied to the data, these functions retrieve the same fraction of variability in $b_{b p}$ and $b_{p}$ (coefficients of determination between 0.82 and 0.88). The $b_{b p}$ coefficient fall within the bounds of previous measurements at intermediate and high [Chl] recently published. Its dependence on [Chl] below $\sim 0.1 \mathrm{mg} \mathrm{m}^{-3}$ is described for the first time with in situ data. The backscattering ratio (i.e. $b_{b p} / b_{p}$ ) with values near 0.01 for all stations appears to be spectrally neutral and not significantly dependent on [Chl]. These results should foster the development of improved forward models of the mean optical properties for oceanic Case 1 waters as well as inverse models based upon them.
\end{abstract}

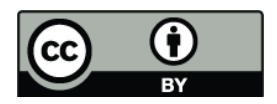

Correspondence to: Y. Huot (huot@obs-vlfr.fr)

\section{Introduction}

The phenomenon of light scattering within a water body is due to water molecules (plus ions) and different types of particles in suspension. Forward scattering corresponds to the fraction of scattering occurring in the forward hemisphere centred on the direction of propagation of the incident radiation. Backscattering occurs in the symmetrical hemisphere centred on the reverse direction. The total scattering coefficient at wavelength $\lambda$ (units are nm), represented by $b(\lambda)$ $\left(\mathrm{m}^{-1}\right)$, is the sum of the coefficients for forward, $b_{f}(\lambda)$, and backward, $b_{b}(\lambda)$, scattering.

There are many reasons for studying the light scattering properties of natural waters. To the extent that the contribution from water molecules is known, scattering properties contain both qualitative and quantitative information about the particles present in the water body. Regarding the backscattering coefficient of marine particles, $b_{b p}(\lambda)$, the two main motivations for studying its magnitude and spectral properties are that: (i) they depend upon, and thus may provide useful information about, the size distribution function and bulk refractive index of the particle population (Ulloa et al., 1994; Morel and Maritorena, 2001; Twardowski et al., 2001), and (ii) the sum of $b_{b p}(\lambda)$ and the backscattering coefficient of pure water, $b_{b w}(\lambda)$, governs the reflectance of the upper layer (Gordon et al., 1975; Morel and Prieur, 1977). The spectral reflectance, $R(\lambda)$ (dimensionless), defined as the ratio of the spectral upward to the downward irradiance just beneath the surface, is essentially related to the ratio $b_{b}(\lambda) / a(\lambda)$, where $a(\lambda)\left(\mathrm{m}^{-1}\right)$ is the spectral absorption coefficient, and $b_{b}(\lambda)=b_{b p}(\lambda)+b_{b w}(\lambda)$ is the total backscattering coefficient of the water body. The changes in the spectral shape of $R(\lambda)$ form the basis of ocean color radiometry

Published by Copernicus Publications on behalf of the European Geosciences Union. 
and its applications. In particular, these changes are used to estimate from space the chlorophyll concentration, [Chl] (mg $\mathrm{m}^{-3}$ ), within the upper layer of oceanic waters (e.g. Clark and Ewing, 1974; O'Reilly et al., 1998).

When building forward models of $R(\lambda)$ as a function of [Chl] (Gordon and Morel, 1983; Gordon et al., 1988; Morel, 1988), empirical relationships derived from field observations were available to describe the mean trend in $a(\lambda)$ as a function of [Chl]. By contrast, analogous relationships have not been established for the quantity $b_{b p}(\lambda)$ and its variation over the full [Chl] range encountered in the open ocean $\left(\sim 0.02-30 \mathrm{mg} \mathrm{m}^{-3}\right)$. This is particularly true of low [Chl] waters as only a very limited amount of $b_{b p}(\lambda)$ data have been published below $0.1 \mathrm{mg} \mathrm{m}^{-3}$. Therefore, modeling studies are necessarily based on assumptions regarding this term (e.g., IOCCG, 2006). Only recently have coincident field data become available for relating [Chl] to $b_{b p}(\lambda)$ (Balch et al., 2001; Reynolds et al., 2001; Twardowski et al., 2001; Stramska et al., 2003; Sullivan et al., 2005; Stramska et al., 2006; Whitmire et al., 2007). A large amount of scatter is present in most of these datasets, which may reflect true natural variability in oceanic waters. However, in some more coastal datasets, terrigeneous particles or sediments probably play a sizeable role in the light backscattering process, which produces larger potential variability in these data (e.g., Fig. 9 in Twardowski et al., 2001). The variability in the $b_{b p}$ vs. [Chl] relationship may also result from experimental uncertainties, which are inevitably attached to the rather difficult measurement of backscattering.

Along the BIOSOPE (BIogeochemistry and Optics South Pacific Experiment) $8000 \mathrm{~km}$-long transect in the eastern South Pacific Ocean (Claustre et al., 2007 ${ }^{1}$ ), $b_{b p}(\lambda)$ measurements were performed with great care and under favorable conditions (Twardowski et al., 2007; Stramski et al., 2008). Moreover, these data were obtained unquestionably in a Case 1 water environment, distant from terrigenous influences, which encompassed a wide [Chl] range from 0.02 to $2 \mathrm{mg} \mathrm{m}^{-3}$. Note that roughly $99 \%$ of the world's ocean has a near-surface [Chl] value within this range (Antoine et al., 2005). Therefore, if a relationship between the magnitudes of $b_{b p}$ and [Chl] actually exists, these contemporaneous measurements in such an environment should reveal it. This is the first aim of the present paper.

Our emphasis will be on the $b_{b p}(\lambda)$ and [Chl] data from the upper layer of the water column, which contributes to the optical signal leaving the ocean detected by ocean color remote sensors. The $b_{b p}(\lambda)$ data from deeper layers are beyond the scope of the present paper. In general, such analyses of backscattering could potentially provide information about the nature of scattering material and its modification along

\footnotetext{
${ }^{1}$ Claustre, H., Sciandra, A., and Vaulot, D.: Introduction to the special section Bio-optical and biogeochemical conditions in the South East Pacific in late 2004: the BIOSOPE program, Biogeosciences Discuss., 5, 605-640, 2008
}

the vertical (e.g. changes in the proportions of living vs. nonliving particles, size distribution of particles and their chemical composition via the refractive index, pigment changes resulting from photoacclimation of algae, and so on).

The second aim of our study is to examine the spectral shape of $b_{b p}(\lambda)$ and to compare it with the spectral behavior of $b_{p}(\lambda)$. In modeling approaches, it is generally postulated that both coefficients follow the same spectral trend, which means that their ratio,

$\tilde{b}_{b p}(\lambda)=b_{b p}(\lambda) / b_{p}(\lambda)$

referred to as the particle backscattering ratio or backscattering probability, $\tilde{b}_{b p}(\lambda)$ (unitless), is spectrally neutral. Actually, this assumption is not supported by theory (Morel and Bricaud, 1981), at least for heavily pigmented particles such as phytoplankton cells, nor by experiments made with pure algae grown in culture (Ahn et al., 1992). This assumption could possibly be an acceptable approximation when dealing with natural particle assemblages because they include a considerable amount of rather colorless debris and tiny heterotrophic organisms (mostly bacteria), viruses, and other numerous small-sized particles which largely contribute to $b_{b p}(\lambda)$ (Morel and Ahn, 1991;Stramski and Kiefer, 1991). A detailed understanding of the contribution of various particle types to $b_{b p}(\lambda)$ remains limited (Stramski et al., 2004). Both the magnitude and spectral behavior of $\tilde{b}_{b p}(\lambda)$ will be examined here on the basis of measurements made in the $\mathrm{Pa}$ cific Ocean. Comparisons with other data sources will also be presented.

\section{Instrumentation and methods}

The particle beam attenuation coefficient, $c_{p}(\lambda)\left(\mathrm{m}^{-1}\right)$, and the sum of absorption coefficients of particulate and dissolved components, $a_{n w}(\lambda)\left(\mathrm{m}^{-1}\right)$, were measured at nine wavelengths with an ac-9 instrument (WET Labs ). From these measurements, the $b_{p}(\lambda)$ coefficient is straightforwardly derived from $b_{p}(\lambda)=c_{p}(\lambda)-a_{n w}(\lambda)$. The backscattering measurements were made at three wavelengths $(462$, 532, and $650 \mathrm{~nm}$ ) by deploying an ECO-BB3 (WET Labs; hereafter referred to as the BB3) profiling instrument. The operation and calibration of these instruments, as well as the methods for processing the raw data to derive $b_{b p}(\lambda)$, are described in detail by Twardowski et al. (2007). Dark offset calibration parameters for the BB3 were measured directly in situ during BIOSOPE for optimal accuracy.

The backscattering coefficient was also determined at eight other wavelengths using a Hydroscat-6 (HOBI Labs, wavebands 442, 470, 550, 589, 620 and $671 \mathrm{~nm}$ ) and two a$\beta$ eta instruments (HOBI Labs, wavebands 420 and $510 \mathrm{~nm}$ ). Note that the Hydroscat band at $620 \mathrm{~nm}$ did not function during the BIOSOPE cruise and that we have removed the band at $671 \mathrm{~nm}$ from the analysis to avoid the potential influence of chlorophyll fluorescence. Because the configuration for 
backscattering measurements is identical for the Hydroscat6 and a- $\beta$ eta instruments, for brevity this dataset is hereafter referred to as the Hydroscat dataset. As in Stramski et al. (2008), the Hydroscat data reported here are derived from fitting a spectral power law model to the measured total backscattering spectra. The processing of these data is described in detail in Stramski et al. (2008), to which the reader is referred. An evaluation of the effect of using different published values for pure water scattering is made in Twardowski et al. (2007; see also Stramski et al., 2008). It was found that this effect upon the derived $b_{b p}(\lambda)$ values can be very significant, especially in oligotrophic and hyper-oligotrophic waters.

The $b_{p}(\lambda)$ and $b_{b p}(\lambda)$ data selected from the quasicontinuous vertical profiles are those within the upper layer which coincide with the sampling depths for pigment determinations (made by high performance liquid chromatography, Ras et al., 2007). The total chlorophyll- $a$ concentration, simply denoted [Chl], is defined as the sum of monovinyl chlorophyll- $a$ (including epimeric and allomeric forms), divinyl chlorophyll- $a$, and chlorophyllide- $a$. The upper layer is operationally defined as the layer between the surface and $z \approx 2 / K_{d}(490)$, where $K_{d}(490)\left(\mathrm{m}^{-1}\right)$ is the attenuation coefficient for downward irradiance at $490 \mathrm{~nm}$. This attenuation coefficient was determined from spectroradiometric measurements of downward irradiance (Morel et al., 2007). The depth $z$ of this layer varied along the whole transect between approximately $20 \mathrm{~m}$ (Chilean upwelling zone) and $85 \mathrm{~m}$ (in the central part of the hyper-oligotrophic gyre).

\section{Theoretical aspects, existing parameterizations and observations}

In contrast to $b_{b p}(\lambda)$, the $b_{p}(\lambda)$ coefficient has been well documented for several decades. A statistical analysis of field data provided a non-linear dependency between $b_{p}(550)$ and [Chl] (Gordon and Morel, 1983, their Fig. 5a)

$b_{p}(550)=0.3[\mathrm{Chl}]^{0.62}$

This initial expression was then revisited by Loisel and Morel (1998) who proposed that particle scattering (at $660 \mathrm{~nm}$ ) for the upper homogeneous layer of the ocean can be empirically related to [Chl] alternatively through one of two relationships. The first general relationship

$b_{p}(660)=0.347[\mathrm{Chl}]^{0.766}$

was obtained when all pairs of available data (number of observations, $\mathrm{N}=850$ ) were considered (data subsets 1,2 and 3 in reference above). The second relationship

$b_{p}(660)=0.252[\mathrm{Chl}]^{0.635}$

was obtained when considering only subsets 2 and 3 from the tropical Atlantic and Pacific and the Mediterranean Sea
$(N=614)$. Data collected in North Atlantic waters (subset 1) showed enhanced $b_{p}(660)$ values, likely due to the presence of coccolithophores or detached liths. For this reason, as discussed in Loisel and Morel (1998), two separate regression analyses were performed leading to Eq. $2 \mathrm{a}$ and $\mathrm{b}$.

The spectral dependency of $b_{p}(\lambda)$ can be explored theoretically (i.e. via Mie theory or van de Hulst's anomalous diffraction approximation) for spherical particles that are assumed to be weakly or non-absorbing, and when their size distribution (in principle with sizes extending from 0 to $\infty$ ) obeys a Junge power function law with an exponent $-j$. In this case, $b_{p}(\lambda)$ strictly varies as $\lambda^{\nu}$, where the exponent $\nu=3-j$ (Morel, 1973). Bader (1970) showed that the Junge law applies generally for marine particles and that a central value for $j$ is approximately 4 . Given this average value for $j$, which has been repeatedly observed, the exponent $v$ would be around -1 and thus the $\lambda^{-1}$ spectral model for scattering is often adopted. Departures from $j=4$ are observed and were indeed found during the BIOSOPE cruise ${ }^{2}$.

As mentioned, the true limitation of the maximal size of natural particles (Boss et al., 2001), and more importantly, the lack of knowledge of the particle size distribution in the sub-micron range (as well as their non-zero absorption), disturbs the rigor of the above relationship between the $v$ and $j$ exponents. In Morel and Maritorena (2001, their Eq. 14), the $\lambda^{-1}$ dependency was kept at the lower limit of the [Chl] range $\left(0.02 \mathrm{mg} \mathrm{m}^{-3}\right)$, and was then progressively reduced toward $\lambda^{0}$ with increasing [Chl] to account for the fact that the bulk particulate matter becomes generally more absorbing (and less scattering) in the blue-green spectral region with increasing $[\mathrm{Chl}]$ over its oceanic range. Based on these assumptions, Eq. $2 \mathrm{a}$ and $\mathrm{b}$ can be extended to other wavelengths according to

$b_{p}(\lambda)=b_{p}(660)\left[\frac{\lambda}{660}\right]^{v}$

where the exponent $v$ is allowed to vary (from -1 to 0 ) as a function of [Chl]

$$
\begin{array}{ll}
\nu([\mathrm{Chl}])=0.5\left(\log _{10}[\mathrm{Chl}]-0.3\right) & \text { when } 0.02<[\mathrm{Chl}]<2 \mathrm{mg} \mathrm{m}^{-3} \\
\begin{array}{ll}
\text { and } \\
\nu=0 & \text { when }[\mathrm{Chl}]>2 \mathrm{mg} \mathrm{m}^{-3} .
\end{array}
\end{array}
$$

In the absence of backscattering measurements, apart from a few studies such as those of Petzold (1972), theoretical computations were necessary (Morel and Bricaud, 1981, 1986). They were made again with Mie theory assuming Junge-type size distributions and reasonable values for the relative refractive index of suspended material (Ulloa et al., 1994; Morel and Maritorena, 2001; Twardowski et al., 2001). Such computations provided the backscattering ratio $\tilde{b}_{b p}(\lambda)$

\footnotetext{
${ }^{2}$ Sciandra, A. Stramski, D., Babin, M. Twardowski, M. S., Grob, C. Diel and spatial variability of the particle size distributions, notably of submicron particles, in the South Pacific Ocean, in preparation, 2007.
} 

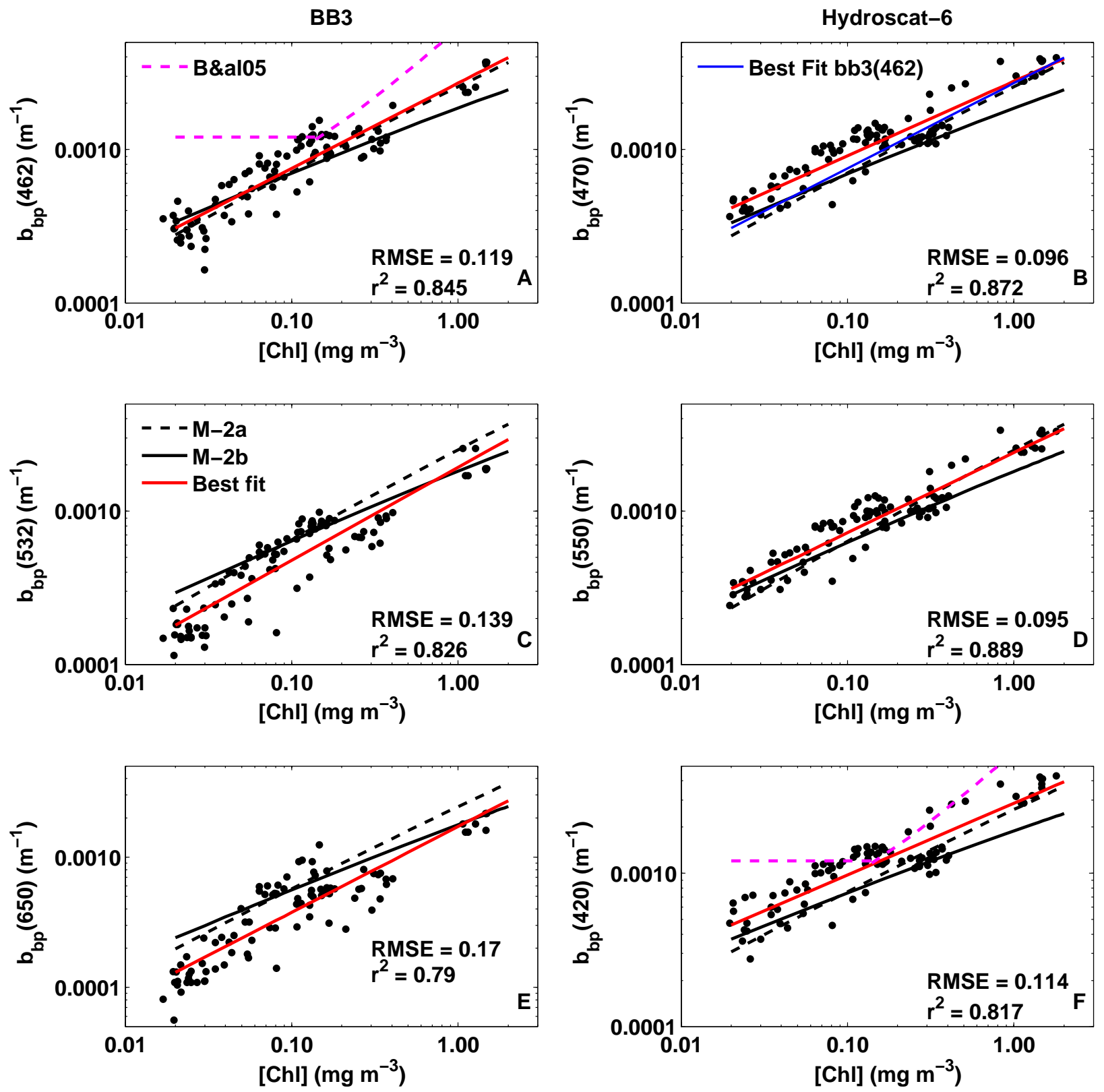

Fig. 1. Particulate backscattering coefficients measured at different wavelengths with two instruments as a function of chlorophyll- $a$ concentration: left column with BB3 (Twardowski et al., 2007) and right column with Hydroscat instruments (Stramski et al., 2008). Twardowski (2007) presents a comparison of these two sensors at $470 \mathrm{~nm}$. In each panel (see the common legend for all panels in panel C) the line of best fit is represented in red; the dashed black curve results from the algorithm of Morel and Maritorena (2001), and the continuous black curve is a modification of the former when Eq. 2 b replaces Eq. $2 \mathrm{a}$ (see text). (A) For $\lambda=462 \mathrm{~nm}$, the magenta dashed line is the bilinear relationship obtained by Behrenfeld et al. (2005) to represent the $b_{b p}$ vs. [Chl] relationship. (B) For $\lambda=470 \mathrm{~nm}$, the blue line represents the best fit to the BB3 data from panel A (at $462 \mathrm{~nm}$ ). (C) For $\lambda=532 \mathrm{~nm}$, (D) For $\lambda=550 \mathrm{~nm}$. (E) For $\lambda=650 \mathrm{~nm}$. (F) For $\lambda=420 \mathrm{~nm}$, the magenta line is the same as in panel A. Equations for the best fit lines are provided in Table 1 along with the other wavebands measured with the Hydroscat. All the RMSE and $r^{2}$ values provided herein were obtained for $\log _{10}$-transformed data.

(Eq. 1). Under the adopted assumptions, the computed values of $\tilde{b}_{b p}(\lambda)$ were rather low, around or below 0.01 for the biogenous material (with low refractive index) typically present in Case 1 waters. Similar computations to simulate pure phytoplankton cultures with their log-normal size distributions provided even lower values $\left(\sim 10^{-3}-10^{-4}\right)$, which were confirmed by experiments (Ahn et al., 1992). In addition, the $b_{b p}(\lambda)$ spectra for algae exhibit features within the 
Table 1. Regression coefficients and statistics of the fits for the particulate backscattering (number of observations $N=97$ for the Hydroscat and $N=92$ for the BB3) and particulate scattering coefficients $(N=77)$ as a function of the chlorophyll concentration.

\begin{tabular}{lclllllll}
\hline \multicolumn{3}{c}{$b_{b p}=\alpha_{1}[\mathrm{Chl}]^{\beta 1}$} & & \multicolumn{3}{c}{$b_{p}=\alpha_{2}[\mathrm{Chl}]^{\beta 2}$} \\
\hline$\lambda$ & $\alpha_{1}\left(\mathrm{CI}^{\boldsymbol{\alpha}}\right)$ & $\beta_{1}\left(\mathrm{CI}^{\boldsymbol{\alpha}}\right)$ & $\mathrm{r}^{2 *}$ & $\mathrm{RMSE}^{*}\left(\mathrm{MAPE}^{\otimes}\right)$ & $\alpha_{2}\left(\mathrm{CI}^{\boldsymbol{\beta}}\right)$ & $\beta_{2}\left(\mathrm{CI}^{\boldsymbol{\alpha}}\right)$ & $\mathrm{r}^{2 *}$ & $\mathrm{RMSE}^{*}\left(\mathrm{MAPE}^{\otimes}\right)$ \\
412 & - & - & - & - & $0.38(0.06)$ & $0.63(0.06)$ & 0.87 & $0.11(22)$ \\
$420^{1,3}$ & $0.0029(0.0003)$ & $0.47(0.05)$ & 0.82 & $0.11(23)$ & $0.36(0.05)$ & $0.61(0.05)$ & 0.87 & $0.11(21)$ \\
440 & - & - & - & - & $0.33(0.04)$ & $0.57(0.05)$ & 0.88 & $0.10(19)$ \\
$442^{1,3}$ & $0.0029(0.0003)$ & $0.47(0.04)$ & 0.85 & $0.10(21)$ & $0.33(0.04)$ & $0.57(0.05)$ & 0.88 & $0.10(19)$ \\
$462^{2,3}$ & $0.0027(0.0003)$ & $0.56(0.05)$ & 0.85 & $0.12(23)$ & $0.33(0.04)$ & $0.58(0.05)$ & 0.88 & $0.10(19)$ \\
$470^{1,3}$ & $0.0028(0.0002)$ & $0.49(0.04)$ & 0.87 & $0.10(19)$ & $0.33(0.04)$ & $0.59(0.05)$ & 0.88 & $0.10(19)$ \\
488 & - & - & - & - & $0.33(0.04)$ & $0.60(0.05)$ & 0.88 & $0.11(20)$ \\
$510^{1,3}$ & $0.0026(0.0002)$ & $0.50(0.04)$ & 0.89 & $0.09(19)$ & $0.33(0.04)$ & $0.60(0.05)$ & 0.88 & $0.11(20)$ \\
$532^{2,3}$ & $0.0019(0.0003)$ & $0.61(0.06)$ & 0.83 & $0.14(29)$ & $0.32(0.04)$ & $0.61(0.05)$ & 0.88 & $0.11(20)$ \\
$550^{1,3}$ & $0.0024(0.0002)$ & $0.52(0.04)$ & 0.89 & $0.10(18)$ & $0.32(0.04)$ & $0.62(0.05)$ & 0.88 & $0.11(21)$ \\
555 & - & - & - & - & $0.32(0.04)$ & $0.62(0.05)$ & 0.88 & $0.11(21)$ \\
$589^{1,3}$ & $0.0022(0.0002)$ & $0.54(0.04)$ & 0.89 & $0.10(19)$ & $0.29(0.04)$ & $0.61(0.05)$ & 0.88 & $0.11(21)$ \\
$650^{2}$ & $0.0017(0.0003)$ & $0.66(0.07)$ & 0.79 & $0.17(31)$ & $0.26(0.04)$ & $0.58(0.05)$ & 0.87 & $0.11(21)$ \\
676 & - & - & - & - & $0.24(0.03)$ & $0.59(0.05)$ & 0.87 & $0.11(21)$ \\
715 & - & - & - & - & $0.27(0.04)$ & $0.60(0.05)$ & 0.88 & $0.11(20)$ \\
\hline
\end{tabular}

${ }^{1}$ Hydroscat backscattering data.

2 BB3 backscattering data.

3 Scattering data interpolated to the BB3 and Hydroscat wavebands.

* $95 \%$ confidence interval on the parameters.

* On the decimal log transformed data (unitless).

$\otimes$ Mean absolute percent error $=\frac{100}{N} \sum_{i}\left|\left(\hat{y}_{i}-y_{i}\right) / y_{i}\right|$ where $N$ is the number of samples, $\hat{y}_{i}$ is the estimated value and $y_{i}$ is the measured value of the ith sample.

pigment absorption bands. Such a spectral dependency, however, is not expected for most natural particle assemblages. In the open ocean, except in bloom conditions, phytoplankton cells are postulated to contribute only a small amount to $b_{b p}(\lambda)$ while other smaller particles have a dominant influence. In particular, these other particles include small-sized non-living particles with perhaps sizable contributions of heterotrophic microbes (Morel and Ahn, 1991; Stramski and Kiefer, 1991) and of coccoliths if present in sufficient concentrations (Balch et al., 2001). The quasi-neutral character of $\tilde{b}_{b p}(\lambda)$ within the visible spectrum has been recently observed in field experiments (Whitmire et al., 2007).

In Morel and Maritorena (2001, see their Eq. 13 ), $\tilde{b}_{b p}$ is spectrally flat. Under this assumption the spectral dependency of $b_{b p}(\lambda)$ follows that of $b_{p}(\lambda)$ as expressed by Eqs. 3 and 4 . The $\tilde{b}_{b p}$ is also posited to depend on [Chl] according to

$\tilde{b}_{b p}=0.002+0.01\left(0.50-0.25 \log _{10}[\mathrm{Chl}]\right)$

A model representing the spectral backscattering coefficient is thus obtained as follows. Upon rearranging Eq. 1, $b_{b p}(\lambda)$ is expressed as $b_{b p}(\lambda)=\tilde{b}_{b p} b_{p}(\lambda)$ and $\tilde{b}_{b p}(\lambda)$ is obtained from Eq. 5 so that $\tilde{b}_{b p}$ decreases from 0.012 to 0.007 when [Chl] increases from 0.01 to $1 \mathrm{~g} \mathrm{~m}^{-3}$. The $b_{p}(660)$ val- ues utilized here are those computed as a function of [Chl] by using Eq. 2a, or Eq. $2 \mathrm{~b}$ thus providing two expressions for $b_{b p}(\lambda)$ referred to respectively as M-2a, and M-2b. Equations 3 and 4 are then applied to obtain the $b_{p}(\lambda)$ values at appropriate wavelengths.

Recent field measurements have provided the first empirical expressions of the backscattering ratio as a function of [Chl]. For all their data from Case 1 waters, Twardowski et al. (2001) arrived at

$\tilde{b}_{b p}(532)=0.0096[\mathrm{Chl}]^{-0.253}$

whereas Whitmire et al. (2007), considering only the data determined within the upper layer, obtained the following relationship

$\tilde{b}_{b p}(555)=0.0074[\mathrm{Chl}]^{-0.042}$

Although these relationships are statistically significant, there is a large amount of scatter around the fits and both studies covered only restricted $[\mathrm{Chl}]$ ranges. From these two datasets and according to Eqs. 6 and 7, $\tilde{b}_{b p}$ thus appears to have a weak or no dependency on [Chl]. The study of Stramska et al. (2006) in the north polar Atlantic observed a slightly increasing $\tilde{b}_{b p}$ with decreasing [Chl] and showed 

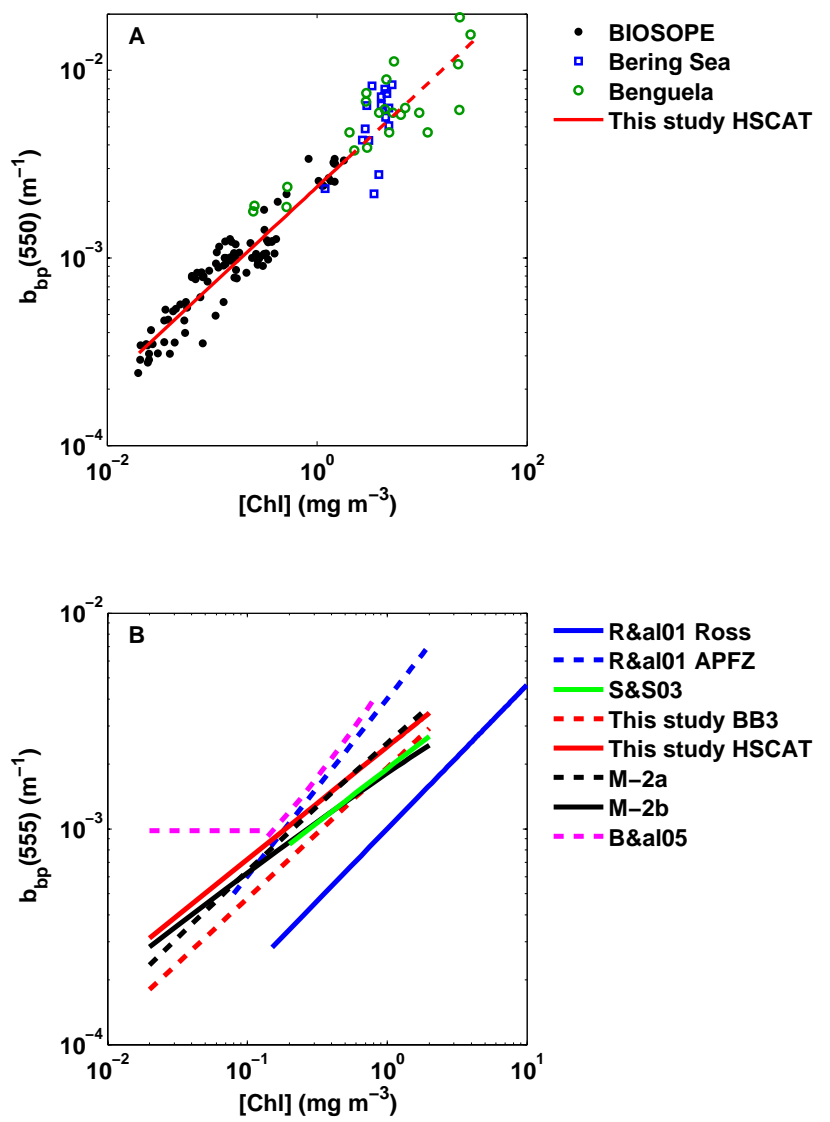

Fig. 2. Extension beyond $2 \mathrm{mg} \mathrm{chl} \mathrm{m}^{-3}$ of the relationship between particulate backscattering coefficient at $555 \mathrm{~nm}$ and the concentration of chlorophyll- $a$ and comparison with previously published relationships. (A) Superimposed onto the BIOSOPE data from Fig. 1d are two datasets with higher chlorophyll concentration. The first was obtained in the Bering Sea with a Hydroscat-6 instrument and the second obtained in the Benguela upwelling system by simultaneous inversion of the diffuse attenuation coefficient and the irradiance reflectance (Morel et al., 2006). The red line is the best fit obtained in Fig. 1d for the range of [Chl] encountered during BIOSOPE, the dashed part is the extension of this fit up to [Chl] of $30 \mathrm{mg} \mathrm{chl} \mathrm{m}^{-3}$. (B) The top five curves (see legend) were obtained using in situ data from the studies of Reynolds et al. (R\&al01, 2001) in (i) the Ross Sea and (ii) the Antarctic Polar Front Zone, (APFZ), (iii) Stramska and Stramski (S\&S03, 2003) in the North Polar Atlantic and from our studies using (iv) the BB3 at $532 \mathrm{~nm}$ (this study BB3), and ( $v$ ) the Hydroscat at $550 \mathrm{~nm}$ (this study HSCAT). The following two curves, M-2a and M-2b, were obtained from Eq. $2 a$ and b respectively, and Eqs. 3, 4 and 5 (see text for details). The last curve was obtained by Behrenfeld et al. (B\&al05, 2005) from remote sensing data (MODIS AQUA sensor) using the model described in Maritorena et al. (2002). We have applied a spectral dependence of $\lambda^{-1.03}$ to transfer the curve reported at $440 \mathrm{~nm}$ to $555 \mathrm{~nm}$ consistent with the slope used by the GSM model (Maritorena et al., 2002). that $\tilde{b}_{b p}$ varied roughly by a factor of two to three for a given [Chl] depending on season for the same oceanic region. They did not, however, provide a functional fit to their data, which showed significant scatter. The relationship obtained by Sullivan et al. (2005), shows even more scatter and deals exclusively with coastal waters around the United States, where the influence of mineral particles is likely frequent and important. Again in US coastal waters, Snyder et al. (2008) found highly variable backscattering ratios (between 0.005 to 0.06 ) but did not relate their results to [Chl].

\section{Results}

In what follows we will first examine the dependence of the spectral backscattering coefficient on [Chl]. Then, we will carry out a similar analysis for the spectral scattering coefficient. Finally, we will focus on the backscattering ratio.

The particle backscattering coefficients as obtained with the BB3 and Hydroscat instruments are displayed for several wavelengths as a function of [Chl] for all stations of the BIOSOPE cruise in Fig. 1. Note that Twardowski et al. (2007) also present a comparison of BIOSOPE data between these two sensors at $470 \mathrm{~nm}$ (see also Stramski et al., 2008 for an analysis of Hydroscat data). Regardless of the wavelength, the $b_{b p}(\lambda)$ values increase rather regularly with increasing [Chl] for both instruments. Such increases of $b_{b p}(\lambda)$ are not unexpected because $b_{p}(\lambda)$ is known to show a steadily increasing trend with increasing [Chl] (e.g. Gordon and Morel, 1983) and, to the extent that $\tilde{b}_{b p}(\lambda)$ is expected to be sufficiently stable, the variations in $b_{b p}(\lambda)$ must roughly follow those of $b_{p}(\lambda)$.

A high correlation between $b_{b p}(\lambda)$ and [Chl] is observed on log-transformed data in Fig. 1 (see $r^{2}$ in each panel and in Table $1 ; r^{2}$ and RMSE are provided for the decimal logtransformed data). The straight red line representing the best fit is plotted in Fig. 1, and it can be compared to the two models (M-2a and M-2b) for $b_{b p}(\lambda)$. While the fit and models do not coincide, the models provides a reasonably accurate description of the slope and amplitude within their respective uncertainties. For M-2a, which is apparently the best model for this dataset, the largest differences occur at $650 \mathrm{~nm}$ where the model overestimates the data by a factor of $\sim 2$. Ostensibly, the regular linear increase in log space extends beyond the [Chl] domain encountered during the BIOSOPE cruise as demonstrated by Fig. 2a. In this figure, in addition to the results from the BIOSOSPE cruise, are displayed $b_{b p}(550)$ values measured in the Bering Sea (with [Chl] near $5 \mathrm{mg} \mathrm{m}^{-3}$ ) and data obtained by the simultaneous inversion of the diffuse attenuation coefficient and irradiance reflectance in the eutrophic waters ([Chl] between 0.2 and $30 \mathrm{mg} \mathrm{chl} \mathrm{m}^{-3}$ ) of the Benguela upwelling system (Morel et al., 2006).

The measurements made during the BIOSOPE cruise in low [Chl] waters agree with to those obtained during other cruise in case 1 waters with moderate to high [Chl]. Indeed, 
apart from measurements in the Ross Sea, a comparison of the regression lines obtained in this study with previously described relationships of $b_{b p}(\lambda)$ vs. [Chl] for Case 1 waters measured in situ show a good consistency (Fig. 2b).

Prior to the present analysis, only the study of Behrenfeld et al. (2005) provided a functional relationship for [Chl] below $0.10 \mathrm{mg} \mathrm{m}^{-3}$ (shown in Fig. 1 panels $\mathrm{A}$ and $\mathrm{F}$ and Fig. 2b), but it was derived from remote sensing data not from in situ data. That relationship shows a levelling off of $b_{b p}(440)$ near a value of $0.0012 \mathrm{~m}^{-1}$ for [Chl] below $0.14 \mathrm{mg}$ $\mathrm{m}^{-3}$. In contrast, the models of $b_{b p}(\lambda)$ based on measurements of $b_{p}(\lambda)$ combined with hypotheses on the dependence of $\tilde{b}_{b p}(\lambda)$ on [Chl] (Eqs. 2a, 2b, 3, 4, and 5) suggest a continuous decrease of $b_{b p}(\lambda)$ with decreasing [Chl] at all wavelengths. The present measurements agree better with these models compared to the proposition of Behrenfeld et al. (2005) especially at low [Chl].

For describing the dependence of $b_{b p}(\lambda)$ on [Chl] using the direct measurements of $b_{b p}(\lambda)$, a model such as the one provided by the set of equations 2 through 5 can be simplified to a single equation, as there is no need for the parameterization of the intermediate term $\tilde{b}_{b p}(\lambda)$. A spectrally resolved empirical model of $b_{b p}(\lambda)$ (between 420 and $650 \mathrm{~nm}$ ) can be written as:

$b_{b p}(\lambda)=\alpha_{1}(\lambda)[\mathrm{Chl}]^{\beta_{1}(\lambda)}$

where $\alpha_{1}(\lambda)$ and $\beta_{1}(\lambda)$ are the multiplicative coefficient and an exponent obtained from fitting a power function to the data, respectively (Table 1 and Fig. 3). It is also found that the parameter $\alpha_{1}(\lambda)$ decreases linearly with wavelength

$\alpha_{1}(\lambda)=2.267 \times 10^{-3}-5.058 \times 10^{-6}(\lambda-550)$

for both the Hydroscat and BB3 datasets, although the Hydroscat dataset shows concave residuals while the BB3 dataset shows convex residuals. The slope parameter, $\beta_{1}(\lambda)$, also depends linearly on wavelength for both instruments, but the relationships differ slightly (see caption Fig. 3). Because there is no clear reason to assume that the data from one of the instruments are better compared to those of the other instrument, a mean relationship for $\beta_{1}(\lambda)$ can be adopted as follows ("proposed" curve in Fig. 3)

$\beta_{1}(\lambda)=0.565+0.000486(\lambda-550)$

This relationship when applied to the whole dataset $(n=858)$ provides an mean absolute percent error (see Table 1 for definition) of $25.2 \%$, an RMSE on the decimal log transformed data of 0.134 and a coefficient of determination of $r^{2}=0.87$. The slight deviation from the general trend of the BB3 data at $532 \mathrm{~nm}$ shown in Fig. 3a and the relatively small discrepancy in the measured $\beta_{1}(\lambda)$ between the two instruments likely originate, at least partly, from differences in calibration and processing methods between them (described in details in Twardowski et al., 2007; Stramski et al., 2008).
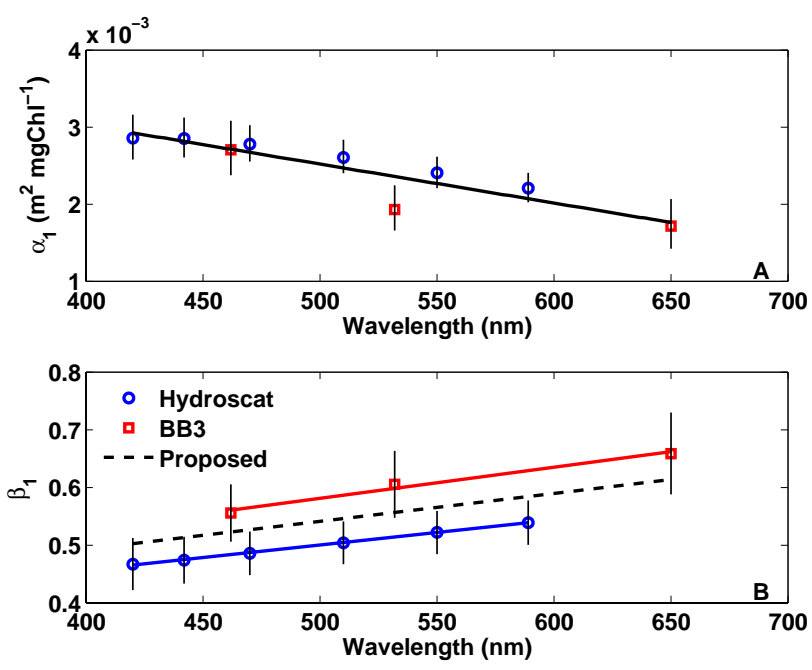

Fig. 3. Spectral dependencies of the parameters for the equation $b_{b p}(\lambda)=\alpha_{1}(\lambda)[C h l]^{\beta_{1}(\lambda)}$ that describes the relationship between the particulate backscattering coefficients $b_{b p}(\lambda)$ and [Chl]. (A) $\alpha_{1}(\lambda)$ vs. $\lambda$ The black line is the best fit represented by a linear model. Note that this departs from the power law often adopted; given the uncertainty in the data we adopted the simplest representation. A power law fit gives a value of 1.14 for the "spectral slope" (i.e. $v$ in Eq. 3 assuming a spectrally flat $\left.\tilde{b}_{b p}(\lambda)\right)$. (B) $\beta_{1}(\lambda)$ vs. $\lambda$. The continuous red and blues lines are best fits of linear models to the data points from the BB3, $\beta_{1}^{B B 3}(\lambda)=0.608+0.000538(\lambda-550)$, and Hydroscat, $\beta_{1}^{\text {Hydroscat }}(\lambda)=0.522+0.000434(\lambda-550)$, instruments respectively. The dashed black line is the proposed model (see Eq. $8 b$ ), which is intermediate between the data from the two instruments. For both panels, the vertical lines represent the $95 \%$ confidence interval on the parameters.

Nevertheless, the differences between the Hydroscat and the BB3 within the present dataset remain small, especially when compared with the natural variability observed in the $b_{b p}(\lambda)$ vs. [Chl] in the ocean (see Fig. 2).

Figure 4 shows the $b_{p}(\lambda)$ data as a function of [Chl] for the same stations and depths as presented for the backscattering coefficient. The best fit to the data and the modelled curves are derived similarly to those in Fig. 1 (except that Eq. 5 is not used) and are also displayed in Fig. 4. The distribution of the data and the fits $\left(r^{2}\right.$ and RMSE in Table 1) demonstrate that scattering by particulate material is highly correlated with [Chl], (an already established fact in case 1 waters) and that the previous formulations of these relationships (i.e. Eq. 2a and b) remain generally applicable to the eastern South Pacific waters. The empirical relationship of $b_{p}(\lambda)$ vs. [Chl], analogous to the one developed above for $b_{b p}(\lambda)$, is thus expressed as

$b_{p}(\lambda)=\alpha_{2}(\lambda)[\mathrm{Chl}]^{\beta_{2}(\lambda)}$

The spectral dependencies of the regression parameters (see Table 1 for $\alpha_{2}(\lambda)$ and $\beta_{2}(\lambda)$ values) shows a linearly 

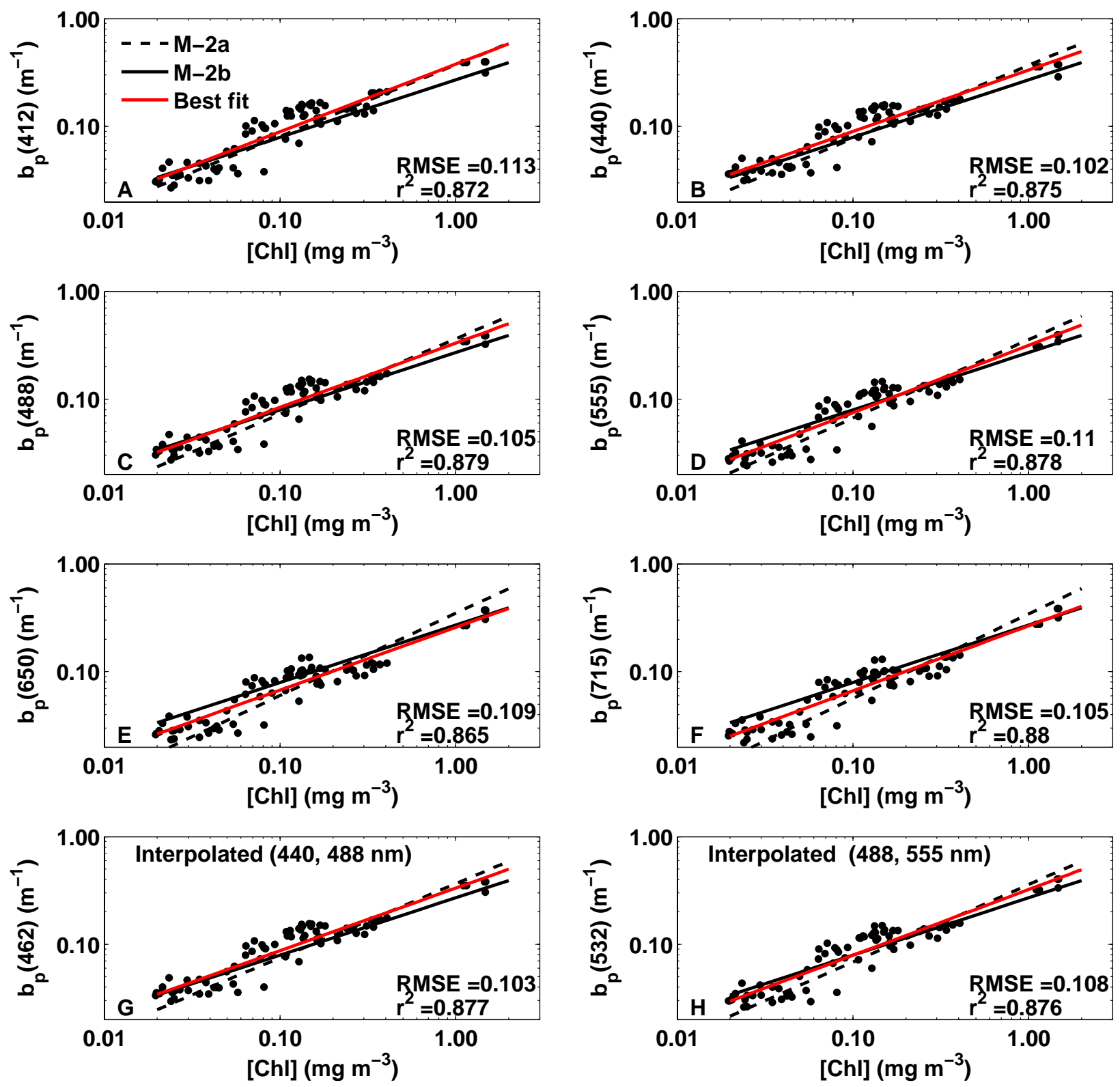

Fig. 4. As in Fig. 1, but for the particle scattering coefficient derived from measurements with the ac-9 instrument. For the two lower panels, the data have been interpolated between the wavelengths available on the ac- 9 to match the wavelengths of the BB3 instrument.

decreasing trend for $\alpha_{2}(\lambda)$ and a rather constant value for $\beta_{2}(\lambda)$ (Fig. 5)

$\alpha_{2}(\lambda)=0.309-0.000384(\lambda-550)$

and

$\beta_{2}(\lambda)=0.60$.

This relationship when applied to the whole dataset $(n=616)$ provides an mean absolute percent error (see Table 1 for definition) of $25.2 \%$, an RMSE on the decimal log transformed data of 0.125 and a coefficient of determination of $r^{2}=0.88$. Given the spectral shape of $\alpha_{2}(\lambda)$ (Fig. 5a) it is tempting to interpret the faint spectral features in terms of phytoplankton absorption effects. However, the magnitude of the confidence interval for the estimates of $\alpha_{2}(\lambda)$ hardly allow such an interpretation. These results are very similar and certainly not significantly different from those presented by Gordon and Morel (1983) at $550 \mathrm{~nm}$ (Eq. 2) and Loisel and Morel (1998) at $660 \mathrm{~nm}$ (though closer to Eq. 2b at this waveband).

Additional useful information can be obtained from Figs. 1 and 4, and associated statistical analyses. Firstly and 

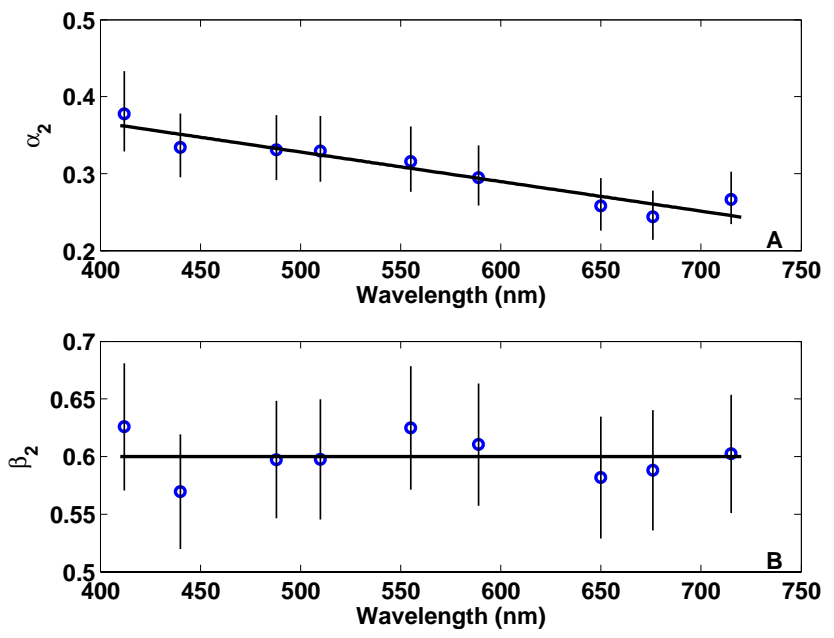

Fig. 5. Spectral dependencies of the parameters in the equation $b_{p}(\lambda)=\alpha_{2}(\lambda)[C h l]^{\beta_{2}(\lambda)}$ that describe the relationship between $b_{p}(\lambda)$ and [Chl]. (A) The black line represents a linear model fitted to the data. A power law fit to $\alpha_{2}$ give a value of -0.70 for the "spectral slope" (i.e. $v$ in Eq. 3). B) The black line represents the average of all data. See Fig. 3 for other relevant details and Eq. 9a and $9 \mathrm{~b}$ for values of the fitted parameters.

somewhat surprinsingly, the fits for $b_{b p}(\lambda)$ vs. [Chl] are as good as those for $b_{p}(\lambda)$ (see Table 1) and secondly, the best fit regression formulas for $b_{b p}(\lambda)$ and $b_{p}(\lambda)$ vs. [Chl] are both of the same form, i.e., $b_{b p}(\lambda)$ or $b_{p}(\lambda)$. Under the condition that phytoplankton are not the particles responsible for most of the particulate backscattering but contribute more efficiently to particulate scattering, these results imply a conspicuously tight link between phytoplankton biomass and other, mostly biogeneous, tiny particles.

Therefore, the ratios of spectrally matched $b_{b p}(\lambda)$ and $b_{p}(\lambda)$ from power function fits result in the particulate backscattering ratio

$\tilde{b}_{b p}(\lambda)=\frac{b_{b p}(\lambda)}{b_{p}(\lambda)}=\frac{\alpha_{1}(\lambda)[\mathrm{Chl}]^{\beta_{1}(\lambda)}}{\alpha_{2}(\lambda)[\mathrm{Chl}]^{\beta_{2}(\lambda)}}$.

For any given wavelength, the average value of $\tilde{b}_{b p}(\lambda)$ when $[\mathrm{Chl}]=1 \mathrm{mg} \mathrm{m}^{-3}$ is provided by the ratio $\alpha_{1}(\lambda) / \alpha_{2}(\lambda)$ while its variation with $[\mathrm{Chl}]$ is expressed through an exponent which amounts to the difference $\beta_{1}(\lambda)-\beta_{2}(\lambda)$.

The results of these computations are presented in Table 2 . They differ slightly depending on whether the BB3 or the Hydroscat datasets are used. Using the BB3 data, the $\tilde{b}_{b p}$ values at the three wavelengths are similar and the mean value is 0.0069 . The mean value of the exponent is -0.02 , when we disregard the wavelength $650 \mathrm{~nm}$ where the RMSE for $b_{b p}$ is higher. On average within the spectrum, $\tilde{b}_{b p}$ can thus be expressed as

$\tilde{b}_{b p}=0.0069[\mathrm{Chl}]^{-0.02}$
Table 2. Parameters describing the relationship between the backscattering ratio and chlorophyll $\left(\tilde{b}_{b}=A[\mathrm{Chl}]^{B}\right)$.

\begin{tabular}{lll}
\hline Wavelength & $\mathrm{A}\left(\mathrm{m}^{2} \mathrm{mg} \mathrm{Chl}^{-1}\right)$ & $\mathrm{B}$ (unitless) \\
\hline $420^{1}$ & 0.0078 & -0.14 \\
$442^{1}$ & 0.0085 & -0.10 \\
$462^{2}$ & 0.0081 & -0.03 \\
$470^{1}$ & 0.0084 & -0.10 \\
$510^{1}$ & 0.0080 & -0.10 \\
$532^{2}$ & 0.0060 & -0.01 \\
$550^{1}$ & 0.0076 & -0.10 \\
$589^{1}$ & 0.0075 & -0.07 \\
$(650)^{2}$ & 0.0067 & 0.08 \\
Average BB3 & 0.0069 & $-0.02^{*}$ \\
Average Hydroscat & 0.0080 & -0.10 \\
Average Hydroscat and BB3 & 0.0077 & $0.081^{*}$ \\
\hline
\end{tabular}

${ }^{1}$ Hydroscat backscattering data.

2 BB3 backscattering data.

* Without $650 \mathrm{~nm}$, which shows a higher RMSE for $b_{b p}$.

For the whole BB3 dataset, including $650 \mathrm{~nm}$, the expression has a mean absolute percent error of $28.4 \%$, and a coefficient of determination of $r^{2}=0.05$, the latter reflecting the absence of variability with [Chl]. This expression is close to that of Whitmire et al. (2007) (see Eq. 7 above) and means that the $\tilde{b}_{b p}$ tends to be independent from [Chl] (the exponent is not significantly different from 0 ), at least for the range of concentrations observed in the investigated region. Using the Hydroscat data and averaging over the six wavebands, we find

$\tilde{b}_{b p}=0.0080[\mathrm{Chl}]^{-0.10}$

As the exponent is significantly different from zero, this would suggest a weak dependence of on [Chl], numerically similar to that expressed by Eq. (5). For the whole Hydroscat dataset, the expression has a mean absolute percent error of $16.5 \%$, and a coefficient of determination of $r^{2}=0.28$.

The backscattering ratio can also be analyzed on a measurement-by-measurement basis, i.e. by considering the $\tilde{b}_{b p}$ values produced by the pairs of particle backscattering and particle scattering values obtained directly from measurements for each wavelength. These data are shown in Fig. $6 \mathrm{a}$ for the BB3 and Fig. $6 \mathrm{~b}$ for the Hydroscat. Also are displayed on this figure several proposed relationships namely (i) Eq. 6, and (ii) Eq. 7, (iii) the relationship proposed by Sullivan et al. (2005) for coastal waters, (iv) the "theoretical" expression corresponding to Eq. 5, (v) a similar relationship proposed by Ulloa et al. (1994), and (vi) the curves from Eq. 11a (for Fig 6a) and Eq. 11b (for Fig. 6b). The actual BB3 data are generally below the various curves for low chlorophyll concentrations, except for the relationship of Whitmire et al. (2007). There is also a considerable 

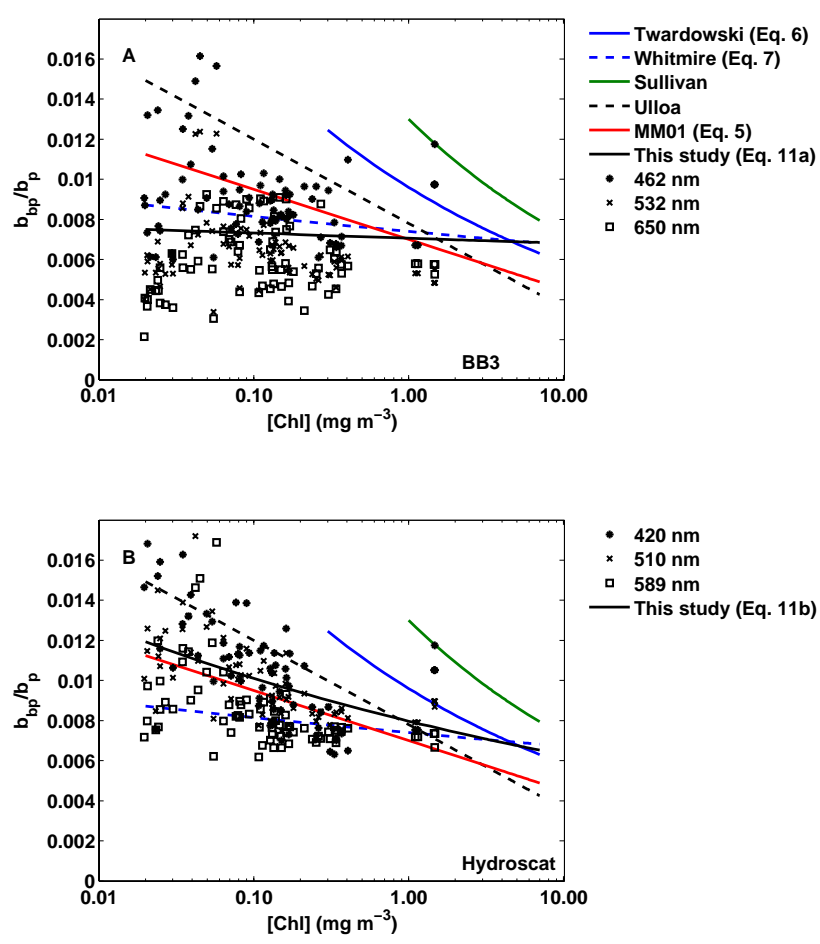

Fig. 6. Data points represent the particulate backscattering ratio, $\tilde{b}_{b p}$, computed from paired values of $b_{b p}$ and $b_{p}$ obtained from the BB3 (panel A), Hydroscat (panel B), and ac-9 measurements, plotted as a function of chlorophyll $a$ concentration, [Chl]. Also included are several curves as follows. The empirical curves are those proposed by Twardowski et al. (2006) (i.e. Eq. 6); Whitmire et al. (2007) (i.e. Eq. 7); and Sullivan et al. (2005) for coastal waters (i.e. $\left.\tilde{b}_{b p}=0.013[\mathrm{Chl}]^{-0.216}\right)$. The empirical curves are limited to the range of $[\mathrm{Chl}]$ in the respective datasets. The curve from a semiempirical model is that proposed by Ulloa et al. (1994), namely $\tilde{b}_{b p}=0.0078-0.0042 \log _{10}$ [Chl]. The curve denoted as "MM01" is obtained according to Morel and Maritorena (2001) (see Eq. 5 in this study). Finally, the curve "This study" represents the spectrally averaged curve obtained in this work (see Eq. 11a for panel A and Eq. $11 \mathrm{~b}$ for panel B).

amount of scatter in the data points regardless of the wavelength. For the Hydroscat, the data points are rather well represented by the Morel-Maritorena (2001) model. A condensed representation of the data points from Fig. 6 in terms of a box-and-whiskers plot is provided in Fig. 7. The median value of $\tilde{b}_{b p}$ for each wavelength is shown with the range of variation (outliers excluded) as well as the corresponding quartiles. Pairs of $b_{b p}(\lambda)$ and $b_{p}(\lambda)$ were also determined within the Benguela upwelling system characterized by moderate to very high [Chl]. From these pairs, the spectral

$\tilde{b}_{b p}(\lambda)$ values have been derived. In Fig. 7 are plotted the average of all $\tilde{b}_{b p}(\lambda)$ values ( $\pm 1 \mathrm{sd}$, pink area) so obtained(see also Fig. 15c in Morel et al., 2006). These $\tilde{b}_{b p}(\lambda)$ ratios superimpose onto, and nicely coincide with those of the South Pacific.

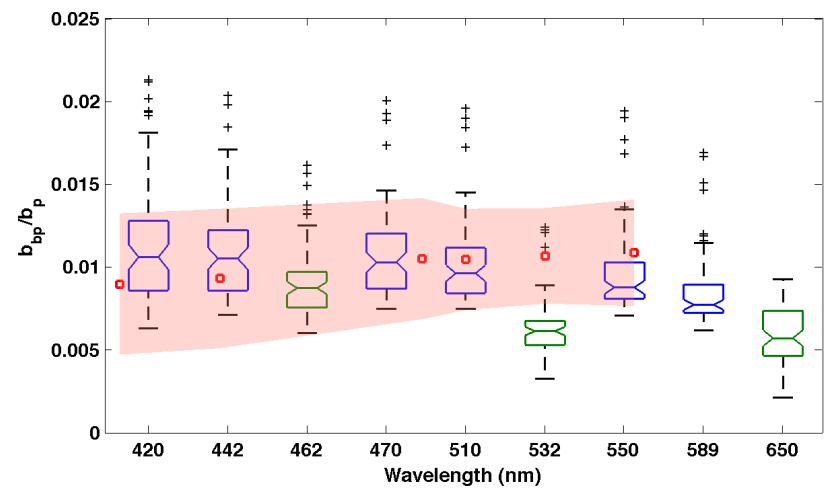

Fig. 7. Box and whiskers plot of $\tilde{b}_{b p}(\lambda)$ for each wavelength, which illustrates the relative distribution of data around the median. The height of the boxes represents the two central quartiles (25\% to 50\% and $50 \%$ to $75 \%$ ). The horizontal bars (whiskers) show the extreme deviations ( 1.5 times the interquartile range), and the points outside these values are considered outliers and are individually displayed as black "+". Boxes for which the width of the notch areas (waist) overlap have median values that are not statistically different at the $5 \%$ significance level. The boxes with green and blue lines represent data from the BB3 and Hydroscat instruments, respectively. The red circles represent the average values of all the $\tilde{b}_{b p}(\lambda)$ (i.e. Case 1 and Case $2-Y$ waters, see figure 15 in Morel et al., 2006) obtained by inversion of $K_{d}$ and reflectance for the BENCAL cruise, the colored area represent plus and minus one standard deviation from these values.

Both approaches, namely the indirect one based on the use of the best fits to $b_{b p}(\lambda)$ vs. [Chl] and $b_{p}(\lambda)$ vs. [Chl], and the direct one based on the use of paired measured data of $b_{b p}(\lambda)$ and $b_{p}(\lambda)$, are consistent within the limits of confidence and support the parameterization provided by Eq. 11a and $\mathrm{b}$. Equations 11a and $\mathrm{b}$ do not account for the spectral effects. We could derive the spectral behavior of $\tilde{b}_{b p}(\lambda)$ as well as its change with [Chl] using Eq. 10 by replacing its numerator by the results of Eq. 8 and its denominator by those of Eq. 9. However, the scatter of the points (seen in Fig. 6) underlying these relationships would make any conclusions regarding the results very speculative.

\section{Discussion and Conclusion}

The first aim of the present study was to examine the potential existence and the functional dependence of the relationship between $b_{b p}(\lambda)$ and [Chl]. In particular, we were interested in the low [Chl] waters below $\sim 0.15 \mathrm{mg} \mathrm{m}^{-3}$, which are encountered in approximately $90 \%$ of the ocean surface (Antoine et al., 2005) and where relatively few in situ measurements have been made. The important result presented here is that such empirical relationships exist in Case 1 waters over the full [Chl] range investigated $(0.02-2 \mathrm{mg}$ $\mathrm{m}^{-3}$ ) and can be represented using simple power function of [Chl]. These relationships were also found to be applicable 
to regions with much higher [Chl] (Bering Sea and Benguela upwelling). Furthermore, these relationships are as significant (similar RMSE) as those already established for the particle scattering coefficient, $b_{p}$, and they are wavelength dependent. These results should be helpful in further development and refinement of forward models of ocean color and in the construction of synthetic datasets for inverse modeling purposes (e.g. IOCCG, 2006), particularly at low chlorophyll concentrations.

From a remote sensing perspective, such a description of $b_{b p}(\lambda)$ is particularly important when developing forward models. Indeed, bio-optical and reflectance models require detailed knowledge and parameterization of the average trends in the inherent optical properties, at least within Case 1 waters where these trends can be related to [Chl]. Up until now and in the absence of data, models have relied on assumptions about $b_{b p}(\lambda)$. A common belief was that the light backscattering process is perhaps less predictable than other processes such as total scattering and absorption, and would thus form the weak link in the modelling approaches. According to the present analysis, it seems that this is not the case, since the prediction of $b_{b p}(\lambda)$ from [Chl] would not be worse (nor better, i.e., roughly within a factor of 2 or 3 ) than those for other inherent optical properties.

Prior to this study, two main propositions existed that included [Chl] below $0.1 \mathrm{mg} \mathrm{m}^{-3}$, one formulated by Morel and Maritorena (2001) and the other by Behrenfeld et al. (2005). The latter is based on simultaneous retrievals of $[\mathrm{Chl}]$ and $b_{b p}(\lambda)$ from remotely sensed ocean color radiometric data. Our present experimental findings, which are based on coincident in situ measurements of $b_{p}(\lambda), b_{b p}(\lambda)$, and [Chl] are more consistent with the formulation of Morel and Maritorena (2001) that accounts for a continuously decreasing $b_{b p}(\lambda)$ with decreasing [Chl]. These concomitant decreases contrast with the flat relationship adopted by Behrenfeld et al. (2005) for the low chlorophyll concentrations that predicts an invariant $b_{b p}(440)$ value (near $0.0012 \mathrm{~m}^{-1}$ ) when [Chl] is below $0.14 \mathrm{mg} \mathrm{m}^{-3}$. Actually, Behrenfeld et al. (2005) used the Garver-Siegel-Maritorena inversion model (Maritorena et al., 2002), and a bias in the satellitederived backscattering coefficient probably occurs when this model is used at low [Chl] (see Appendix). This bias may explain the bilinear relationship adopted by Behrenfeld et al. (2005).

Our second aim was to examine if any difference in the spectral behavior of the backscattering and scattering coefficient existed. To this end, we analyzed the particulate backscattering ratio. This analysis shows that $\tilde{b}_{b p}(\lambda)$ is essentially spectrally neutral and its value (around 0.01 ) does not depend on the trophic state of case 1 waters.

The unquestionably case 1 nature of the environment sampled allowed us to obtain the clear trends described herein with limited variability due to external influences. It must, however, be kept in mind that in this region, the influence of aerosol deposition onto the ocean is amongst the lowest in the world's ocean (Gao et al., 2003) and hence extrapolation of these results to other oceanic regions must be made with care. In particular, the relationship for regions in which a greater abundance of mineral particles could play an important role might depart from the relationships derived here.

It is clear that within this paper we present field observations but we do not provide an explanation for the origin of the backscattering in the ocean. Indeed, the backscattering process is associated with tiny particles (Morel and Ahn, 1991;Stramski and Kiefer, 1991), while the scattering process results from the presence of particles of much larger size (by a factor of $\sim 10$ ) such as that of most algal cells. Therefore, the fact that $b_{p}$ is related to [Chl] is naturally expected in case 1 waters, and actually observed. More intriguing is the fact that $b_{b p}$ is also tightly linked to [Chl], which implies that the abundance of tiny, a priori non-algal, particles is, nonetheless, proportional to the abundance of algae. Heterotrophic bacteria and viruses concentration are very likely tightly linked to algal concentration. Their contribution to total backscattering, however, remains limited (Morel and Ahn, 1991;Stramski and Kiefer, 1991). Therefore, the unidentified "missing backscattering term" (probably debris of all kinds?) would also be proportional to the algal concentration, which remains to be explained on a biogeochemical basis.

\section{Appendix}

\section{Examination of the remotely sensed backscattering coefficient in the BIOSOPE zone}

Due to the generally cloudy conditions, a very limited number of satellite and in situ match-up observations were obtained during the BIOSOPE cruise. This unfavorable situation does not provide a sufficient number of data points over a wide [Chl] range to test directly the performance of remote sensing models for backscattering such as those presented by IOCCG (2006). Instead, here we use an indirect approach based on the comparison of satellite-derived [Chl] with satellite-derived backscattering coefficients.

For all scenes acquired by the MODIS AQUA sensor in the BIOSOPE zone during the month of November 2004, we applied two semi-analytical inverse models of ocean color to obtain $b_{b p}(443)$ and extracted the results along the transect (independently of the date). The two models used are the SEADAS 5.1.3 implementations of 1) the Quasi-Analytical Algorithm (QAA, Lee et al., 2002) and 2) the Garver-SiegelMaritorena model (GSM, Maritorena et al., 2002). The backscattering coefficient retrieved from these models is then plotted against [Chl] retrieved with the OC3M algorithm (Fig. A1).

This analysis shows that within the South Pacific Gyre, the GSM model returns nearly constant $b_{b p}$ values below $[\mathrm{Chl}]=0.1 \mathrm{mg} \mathrm{m}^{-3}$. The magnitude of this constant value corresponds roughly to the horizontal portion of the relationship 

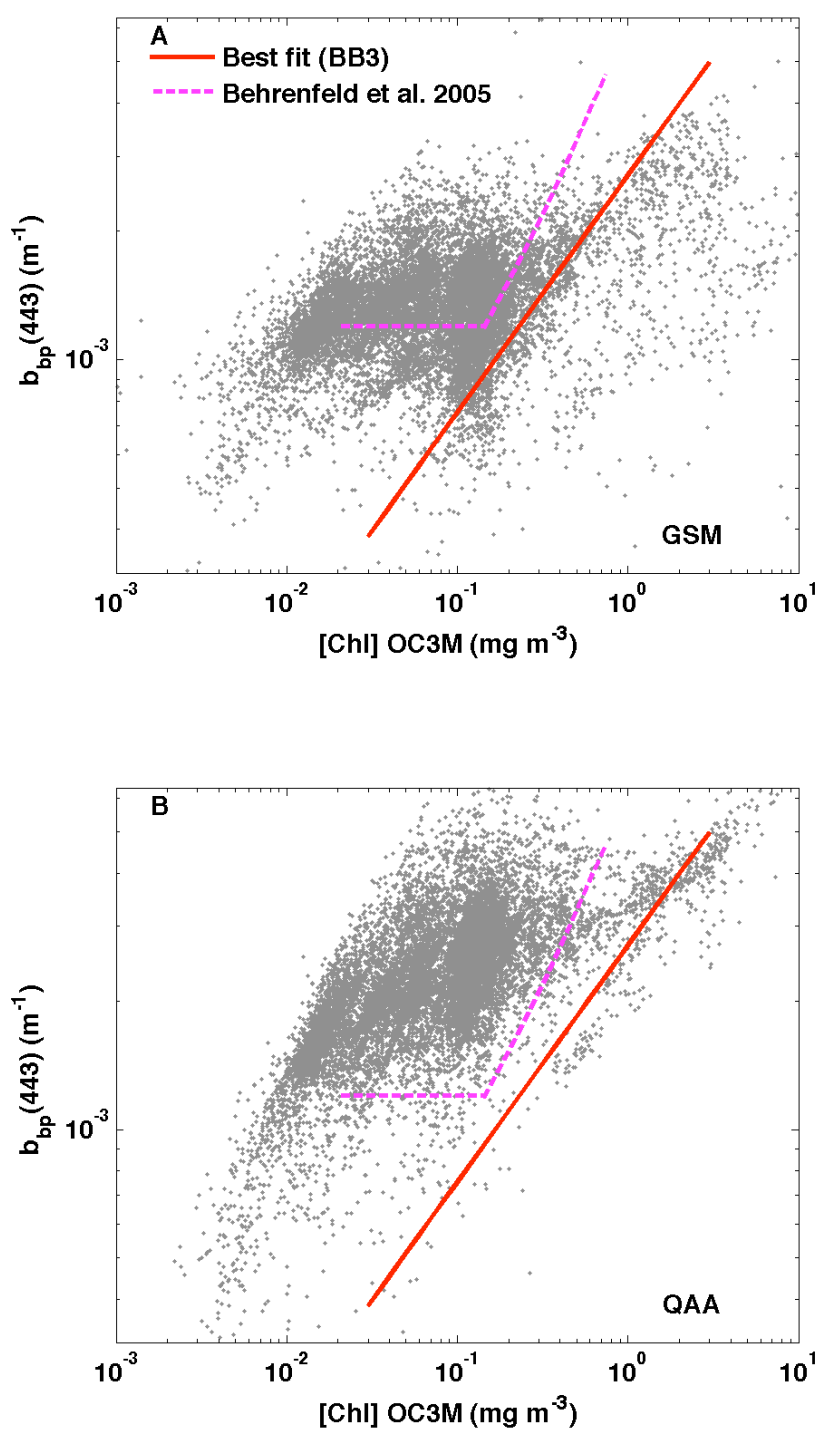

Fig. A1. The particulate backscattering coefficient at $443 \mathrm{~nm}$ retrieved using two ocean color semi-analytical inverse models as a function of the chlorophyll concentration obtained using the OC3M algorithm along the BIOSOPE transect. (A) The GSM model, (B) the QAA model. On both panels the relationships fitted to the BB3 data at $462 \mathrm{~nm}$ as well as the bilinear relationship obtained by Behrenfeld et al. (2005) (at $440 \mathrm{~nm}$ ) are overlaid.

proposed by Behrenfeld et al. (2005). In contrast, the in situ data show continuously decreasing values, which suggest that the horizontal segment in the Behrenfeld et al. (2005) curve originates from biases in the remotely sensed backscattering coefficient, and not from physiological adjustments in phytoplankton. The results obtained using the QAA model show an irregular decrease in the backscattering coefficients, more similar to those measured in the Gyre, except that the slope is less steep leading to an overestimate of the backscattering coefficient by $\sim 270 \%$ relative to the in situ data at $[\mathrm{Chl}]=0.02 \mathrm{mg} \mathrm{m}^{-3}$.
Acknowledgements. D. Tailliez and C. Marec are warmly thanked for their efficient help in CTD rosette management and data processing. Data from the Bering Sea were provided by J. J. Cullen from a research program supported by NOAA/PMEL, NSERC Research Partnerships and the US Office of Naval Research. This is a contribution of the BIOSOPE project of the LEFE-CYBER French program. This research was funded by the Centre National de la Recherche Scientifique (CNRS), the Institut des Sciences de l'Univers (INSU), the Centre National d'Études Spatiales (CNES), the European Space Agency (ESA), the National Aeronautics and Space Administration (NASA) and the Natural Sciences and Engineering Research Council of Canada (NSERC). Y. H. was funded by a postdoctoral scholarship from CNES (France).

Edited by: E. Boss

\section{References}

Ahn, Y. H., Bricaud, A., and Morel, A.: Light backscattering efficiency and related properties of some phytoplankters, Deep-Sea Res. Pt., 39, 1835-1855, 1992.

Antoine, D., Morel, A., Gordon, H. R., Banzon, V. F., and Evans, R. H.: Bridging ocean color observations of the 1980s and 2000s in search of long-term trends, J. Geophys. Res., 110, C06009, doi:10.1029/2004JC002620, 2005.

Bader, H.: The hyperbolic distribution of particle sizes, J. Geophys. Res., 75, 2822-2830, 1970.

Balch, W. M., Drapeau, D. T., Fritz, J. J., Bowler, B. C., and Nolan, J.: Optical backscattering in the arabian sea - continuous underway measurements of particulate inorganic and organic carbon, Deep-Sea Res. Pt. I, 48, 2423-2452, 2001.

Behrenfeld, M. J., Boss, E., Siegel, D. A., and Shea, D. M.: Carbon-based ocean productivity and phytoplankton physiology from space, Global Biogeochem. Cy., 19, GB1006, doi:10.1029/2004GB002299, 2005.

Boss, E., Twardowski, M. S., and Herring, S.: Shape of the particulate beam attenuation spectrum and its inversion to obtain the shape of the particulate size distribution, Appl. Opt., 40, 48854893, 2001.

Clark, G. L., and Ewing, G. C.: Remote spectroscopy of the sea for biological production studies, in: Optical aspect of oceanography, edited by: Jerlov, N. G., and Nielsen, E. S., Academic, New York, 494, 1974.

Gao, Y., Fan, S.-M., and Sarmiento, J. L.: Aeolian input to the ocean through precipitation scavenging: A modeling perspective and its implication for natural iron fertilization in the ocean, J. Geophys. Res., 108, 4221, doi:10.1029/2002JD002420, 2003.

Gordon, H. R., Brown, O. B., and Jacobs, M. M.: Computed relationships between inherent and apparent optical properties of a flat homogeneous ocean, Appl. Opt., 14, 417-427, 1975.

Gordon, H. R. and Morel, A.: Remote assessment of ocean color for interpretation of satellite visible imagery: A review, Lecture notes on coastal and estuarine studies, Springer Verlag, Heidelberg, Germany, 114 pp., 1983.

Gordon, H. R., Brown, O. B., Evans, R. H., Brown, J. W., Smith, R. C., Baker, K. S., and Clark, D. K.: A semianalytic radiance model of ocean color, J. Geophys. Res., 93, 10 909-10 924, 1988. 
IOCCG: Remote sensing of inherent optical properties: Fundamentals, tests of algorithms, and applications, in: Reports of the International Ocean-Colour Coordinating Group, edited by: Lee, Z.-P., No. 5, IOCCG, Dartmouth, Canada, 126, 2006.

Lee, Z. P., Carder, K. L., and Arnone, R. A.: Deriving inherent optical properties from water color: A multiband quasi-analytical algorithm for optically deep waters, Appl. Opt., 41, 5755-5772, 2002.

Loisel, H. and Morel, A.: Light scattering and chlorophyll concentration in case 1 waters: A reexamination, Limnol. Oceanogr., 43, 847-858, 1998.

Maritorena, S., Siegel, D. A., and Peterson, A. R.: Optimization of a semianalytical ocean color model for global-scale applications, Appl. Opt., 41, 2705-2714, 2002.

Morel, A.: Diffusion de la lumière par les eaux de mer. Resultats expérimentaux et approche théorique., AGARD lectures series, 3.1.1-3.1.76, 1973.

Morel, A. and Prieur, L.: Analysis of variations in ocean color, Limnol. Oceanogr., 22, 709-722, 1977.

Morel, A. and Bricaud, A.: Theoretical results concerning the optics of phytoplankton, with special references to remote sensing applications, in: Oceanography from space, edited by: Gower, J. F. R., Plenum, New York, 313-327, 1981.

Morel, A. and Bricaud, A.: Inherent properties of algal cells including picoplankton: Theoretical and experimental results., in: Photosynthetic picoplankton, edited by: Platt, T. and Li, W. K. W., Canadian bulletin of fisheries and aquatic sciences, 521-559, 1986.

Morel, A.: Optical modeling of the upper ocean in relation to its biogenous matter content (case 1 waters), J. Geophys. Res., 93, 10749-10768, 1988.

Morel, A. and Ahn, Y.-H.: Optics of heterotrophic nanoflagellates and ciliates: A tentative assessment of their scattering role in oceanic waters compared to those of bacterial and algal cells, J. Mar. Res., 49, 177-202, 1991.

Morel, A. and Maritorena, S.: Bio-optical properties of oceanic waters: A reappraisal, J. Geophys. Res., 106, 7163-7180, 2001.

Morel, A., Gentili, B., Chami, M., and Ras, J.: Bio-optical properties of high chlorophyll case 1 waters and of yellow-substancedominated case 2 waters, Deep-Sea Res. Pt. I, 53, 1439-1459, 2006.

Morel, A., Gentili, B., Claustre, H., Babin, M., Bricaud, A., Ras, J., and Tièche, F.: Optical properties of the "Clearest" Natural waters, Limnol. Oceanogr., 52, 217-229, 2007.

O'Reilly, J. E., Maritorena, S., Mitchell, B. G., Siegel, D. A., Carder, K. L., Garver, S. A., Kahru, M., and McClain, C. R.: Ocean color chlorophyll algorithms for SeaWiFS, J. Geophys. Res., 103, 24 937-24 953, 1998.

Petzold, T. J.: Volume scattering functions for selected ocean waters, Scripps Institution of Oceanography, Visibility Lab, San Diego, 85, 1972.
Ras, J., Claustre, H., and Uitz, J.: Spatial variability of phytoplankton pigment distributions in the subtropical South Pacific ocean: Comparison between in situ and predicted data, Biogeosciences, 5, 353-369, 2007, http://www.biogeosciences.net/5/353/2007/.

Reynolds, R. A., Stramski, D., and Mitchell, B. G.: A chlorophylldependent semianalytical reflectance model derived from field measurements of absorption and backscattering coefficients within the southern ocean, J. Geophys. Res., 106, 7125-7138, 2001.

Snyder, W. A., Arnone, R. A., Davis, C. O., Goode, W., Gould, R. W., Ladner, S., Lamela, G., Rhea, W. J., Stavn, R., Sydor, M., and Weidemann, A.: Optical scattering and backscattering by organic and inorganic particulates in U.S. Coastal waters, Appl. Opt., 47, 666-677, 2008.

Stramska, M., Stramski, D., Hapter, R., Kaczmarek, S., and Ston, J.: Bio-optical relationships and ocean color algorithms for the north polar region of the Atlantic, J. Geophys. Res., 108, 3143, doi:10.1029/2001JC001195, 2003.

Stramska, M., Stramski, D., Kaczmarek, S., Allison, D. B., and Schwarz, J.: Seasonal and regional differentiation of bio-optical properties within the north polar Atlantic, J. Geophys. Res., 111, C08003, doi:10.1029/2005JC003293, 2006.

Stramski, D. and Kiefer, D. A.: Light scattering by microorganisms in the open ocean, Prog. Oceanogr., 28, 343-383, 1991.

Stramski, D., Boss, E., Bogucki, D., and Voss, K. J.: The role of seawater constituents in light backscattering in the ocean, Prog. Oceanogr., 61, 27-56, 2004.

Stramski, D., Reynolds, R. A., Babin, M., Kaczmarek, S., Lewis, M. R., Röttgers, M., Sciandra, A., Stramska, M., Twardowski, M. S., Franz, B. A., and Claustre, H.: Relationships between the surface concentration of particulate organic carbon and optical properties in the eastern South Pacific and eastern Atlantic oceans., Biogeosciences, 5, 171-201, 2008, http://www.biogeosciences.net/5/171/2008/.

Sullivan, J. M., Twardowski, M. S., Donaghay, P. L., and Freeman, S. A.: Use of optical scattering to discriminate particle types in coastal waters, Appl. Opt., 44, 1667-1680, 2005.

Twardowski, M. S., Boss, E., Macdonald, J. B., Pegau, W. S., Barnard, A. H., and Zaneveld, J. R. V.: A model for estimating bulk refractive index from the optical backscattering ratio and the implications for understanding particle composition in case $i$ and case ii waters, J. Geophys. Res., 106, 14 129-14 142, 2001.

Twardowski, M. S., Claustre, H., Freeman, S. A., Stramski, D., and Huot, Y.: Optical backscattering properties of the "clearest" natural waters, Biogeosciences, 4, 1041-1058, 2007, http://www.biogeosciences.net/4/1041/2007/.

Ulloa, O., Sathyendranath, S., and Platt, T.: Effect of the particlesize distribution on the backscattering ratio in seawater, Appl. Opt., 33, 7070-7077, 1994.

Whitmire, A. L., Boss, E., Cowles, T. J., and Pegau, W. S.: Spectral variability of the particulate backscattering ratio, Opt. Express., 15, 7019-7031, 2007. 